\title{
Gambaran Kebiasaan Bernapas Melalui Mulut dan Gigi Berjejal Anterior pada Siswa SD Negeri 46 Manado
}

\author{
Pansy H. Manalip, ${ }^{1}$ Pritartha S. Anindita, ${ }^{1}$ Lydia E. N. Tendean ${ }^{2}$
}

\author{
${ }^{1}$ Program Studi Pendidikan Dokter Gigi Fakultas Kedokteran Universitas Sam Ratulangi \\ Manado \\ ${ }^{2}$ Bagian Biologi Fakultas Kedokteran Universitas Sam Ratulangi Manado \\ Email: sitinjakagnes@gmail.com
}

\begin{abstract}
Mouth breathing habit during growth and development can affect dentocraniofacial growth. Mouth breathing can cause stunted development of the lower and upper jaws which makes the jaws narrower resulting in crowding teeth. It is a condition of differences in the sizes of the teeth and the arch of the jaw causing teeth overlapping. This study was aimed to obtain the mouth breathing habit and crowding teeth among students of SD Negeri 46 (elementary school) Manado. It was a descriptive study with a cross sectional design. Samples were obtained by using total sampling. Examinations of mouth breathing and crowding teeth were performed on the students and data were analyzed by using percentages. The results showed that $17.2 \%$ of students had mouth breathing habit; $78.5 \%$ of them had crowding teeth. In conclusion, the majority of students of SD Negeri 46 Manado that had mouth breathing habit had crowded teeth.
\end{abstract}

Keywords: mouth breathing, anterior teeth crowding

\begin{abstract}
Abstrak: Kebiasaan bernafas melalui mulut yang berlangsung selama masa tumbuh kembang dapat memengaruhi pertumbuhan dentokraniofasial. Bernapas melalui mulut dapat menyebabkan terhambatnya perkembangan rahang bawah dan rahang atas sehingga rahang menjadi lebih sempit yang berakibat terjadinya gigi berjejal. Kondisi ini merupakan keadaan terdapatnya perbedaan ukuran gigi dan ukuran lengkung rahang, sehingga menyebabkan posisi gigi saling tumpang tindih Penelitian ini bertujuan untuk mengetahui gambaran kebiasaan bernapas melalui mulut dan gigi berjejal anterior pada anak di SD Negeri 46 Manado. Jenis penelitian ialah deskriptif dengan desain potong lintang. Pengambilan sampel menggunakan metode total sampling. Pada penelitian ini dilakukan pemeriksaan bernapas melalui mulut dan pemeriksaan gigi berjejal. Analisis data dilakukan dengan menggunakan persentase. Hasil penelitian mendapatkan 17,2\% subjek penelitian bernapas melalui mulut; $78,5 \%$ di antaranya memiliki gigi berjejal anterior. Simpulan penelitian ini ialah mayoritas anak di SD Negeri 46 Manado yang bernapas melalui mulut memiliki gigi berjejal anterior.
\end{abstract}

Kata kunci: bernapas melalui mulut, gigi berjejal anterior

\section{PENDAHULUAN}

Bernapas merupakan mekanisme vital pada tubuh manusia yang secara normal dilakukan melalui hidung. Bernapas melalui mulut merupakan suatu kelainan cara bernapas. Bernapas melalui mulut disebabkan karena kebiasaan atau adanya gangguan fungsi hidung. Gangguan fungsi hidung antara lain adanya polip, pembesaran ade- noid dan tonsil atau pada pengidap asma. Bernapas melalui mulut jarang dijumpai. Kebiasaan bernapas melalui mulut dilakukan secara tidak sadar, sedangkan jika memiliki gangguan dilakukan secara sadar karena kesulitan bernapas melalui hidung. ${ }^{1}$

Bernapas melalui mulut yang berlangsung selama masa tumbuh kembang dapat memengaruhi pertumbuhan dentokranio- 
fasial. Bernapas melalui mulut dapat memengaruhi bentuk rahang. Saat bernapas melalui mulut, otot-otot memberikan tekanan secara terus-menerus sehingga dapat menyebabkan terhambatnya perkembangan rahang bawah dan rahang atas yang membuat rahang menjadi lebih sempit dan dapat berakibat gigi berjejal. ${ }^{1,2}$

Gigi berjejal merupakan keadaan terdapatnya perbedaan ukuran gigi dan ukuran lengkung rahang sehingga menyebabkan posisi gigi saling tumpang tindih; hal ini dapat terjadi karena kurangnya ruang untuk gigi. Gigi berjejal paling sering terjadi dan paling sering ditemukan pada regio anterior. ${ }^{3,4}$

Gigi berjejal anterior pada anak dapat mengakibatkan beberapa gangguan dilihat dari fungsional kemampuan untuk menggigit dan mengiris makanan terganggu karena posisi gigi yang tidak beraturan. Risiko terkena karies dan penyakit periodontal pada anak dengan gigi berjejal semakin tinggi karena sulitnya untuk membersihkan gigi berjejal tersebut. Gigi berjejal juga dapat memengaruhi psikologis penyandangnya yang menjadi kurang percaya diri karena penampilan.

Berdasarkan data hasil Riset Kesehatan Dasar (Riskesdas) tahun 2018, terdapat $57,6 \%$ penduduk Indonesia yang mengalami masalah gigi dan mulut. Penduduk Sulawesi Utara yang mengalami masalah gigi dan mulut lebih dari $60 \%$. Menurut data dari Pusat Data dan Informasi Kesehatan Republik Indonesia (RI) pada kelompok usia 5-9 tahun terdapat $28,9 \%$ yang mengalami masalah kesehatan gigi dan mulut, dan pada kelompok usia 10-14 tahun terdapat 25,2\% yang mengalami masalah kesehatan gigi dan mulut. ${ }^{2,5}$

Gigi berjejal dapat mulai diamati pada usia 6-12 tahun. Pada saat anak berada diusia 6-12 tahun, gigi tetap dan gigi sulung secara bersama-sama berada di dalam rongga mulut. Pada usia tersebut oklusi masih bersifat sementara dan tidak statis sehingga bila dijumpai maloklusi relatif lebih mudah untuk menanganinya. ${ }^{6}$

Sekolah Dasar (SD) Negeri 46 Manado terletak di Kecamatan Tuminting di ping- giran Kota Manado. Pemilihan populasi dilakukan dengan pertimbangan masalah gigi dan mulut dipengaruhi juga oleh lingkungan tempat tinggal. Di daerah pinggiran kota biasanya kepedulian dan pengetahuan terhadap kesehatan gigi dan mulut lebih rendah dibandingkan dengan masyarakat di wilayah perkotaan. Berdasarkan uraian tersebut, maka penulis tertarik untuk mengetahui gambaran kebiasaan bernapas melalui mulut dan gigi berjejal anterior pada anak di SD Negeri 46 Manado.

\section{METODE PENELITIAN}

Penelitian ini dilaksanakan pada bulan Februari-Agustus 2019 di SD Negeri 46 Manado. Jenis penelitian ini ialah deskriptif dengan desain potong lintang. Populasi penelitian ini yaitu seluruh siswa SD Negeri 46 Manado yang berusia 6-12 tahun. Berdasarkan survei awal anak yang berusia 6-12 tahun berjumlah 165 siswa. Sampel penelitian ini diperoleh dengan menggunakan metode total sampling. Dalam penelitian ini sampel yang memenuhi kriteria inklusi dan eksklusi berjumlah 64 siswa.

Pengumpulan data dilakukan dengan pemeriksaan langsung pada siswa. Data yang dikumpulkan yakni cara bernapas anak dan keadaan gigi anterior pada rahang atas dan rahang bawah anak. Orang tua anak sebelumnya diberikan lembar penjelasan dan informed consent beberapa hari sebelum dilaksanakan penelitian.

Pengambilan data kebiasaan bernapas melalui mulut dilakukan menggunakan metode tes kaca mulut dua arah lalu ditentukan subjek penelitian bernapas melalui mulut atau tidak. Pengambilan data gigi berjejal anterior dilakukan melalui pemeriksaan gigi anterior pada rahang atas atau rahang bawah. Subjek penelitian diarahkan untuk membuka rongga mulut dan diperiksa dengan menggunakan kaca mulut yang telah disterilkan untuk melihat apakah terdapat gigi berjejal pada bagian anterior atau tidak.

Analisis data dilakukan dengan melihat persentase data. Data yang diperoleh disajikan dalam bentuk tabel 


\section{HASIL PENELITIAN}

Penelitian ini dilakukan di Sekolah Dasar Negeri 46 Jalan Gurita Nomor 08 Kelurahan Tumumpa Dua Kecamatan Tuminting Kota Manado Sulawesi Utara. Tabel 1 memperlihatkan karakteristik subjek penelitian yang dikelompokkan berdasarkan jenis kelamin. Pada penelitian ini siswa laki-laki lebih banyak dibandingkan siswa perempuan (53\% vs $47 \%$ ).

Tabel 1. Distribusi subjek penelitian berdasarkan jenis kelamin

\begin{tabular}{|c|c|c|}
\hline $\begin{array}{c}\text { Jenis } \\
\text { kelamin }\end{array}$ & $\mathbf{n}$ & $\%$ \\
\hline Perempuan & 30 & 47 \\
\hline Laki-laki & 34 & 53 \\
\hline Total & 64 & 100 \\
\hline
\end{tabular}

Tabel 2 memperlihatkan karakteristik subjek penelitian yang dikelompokkan berdasarkan usia. Siswa berusia 8 tahun merupakan subjek terbanyak $(29,7 \%)$, sedangkan yang paling sedikit ialah siswa berusia 7 tahun $(7,9 \%)$.

Tabel 2. Distribusi subjek penelitian berdasarkan usia

\begin{tabular}{ccc}
\hline Usia & n & \% \\
\hline 7 & 5 & 7,9 \\
8 & 19 & 29,7 \\
9 & 13 & 20,3 \\
10 & 16 & 25 \\
11 & 11 & 17,1 \\
Total & 64 & 100 \\
\hline
\end{tabular}

Siswa yang menjadi subjek penelitian ini diperiksa cara bernapasnya melalui mulut atau hidung. Tabel 3 memperlihatkan cara bernapas siswa yang diperiksa dengan metode tes kaca mulut. Pada penelitian ini persentase siswa yang bernapas melalui hidung lebih tinggi yaitu sebanyak 53 siswa $(82,9 \%)$ sedangkan yang bernapas melalui mulut sebanyak 14 siswa $(17,2 \%)$.

Tabel 4 memperlihatkan subjek penelitian yang bernapas melalui mulut dan keadaan gigi anteriornya, berjejal atau tidak berjejal. Dari 14 subjek penelitian yang bernapas melalui mulut sebanyak 11 siswa $(78,5 \%)$ memiliki gigi berjejal anterior
Tabel 3. Distribusi subjek penelitian berdasarkan cara bernapas

\begin{tabular}{lcc}
\hline \multicolumn{1}{c}{ Cara bernapas } & n & \% \\
\hline Melalui mulut & 14 & 17,2 \\
Melalui hidung & 53 & 82,8 \\
Total & 64 & 100 \\
\hline
\end{tabular}

Tabel 4. Distribusi subjek yang bernapas melalui mulut dan kondisi gigi anterior

\begin{tabular}{lcc}
\hline Gigi berjejal & $\mathbf{n}$ & $\mathbf{\%}$ \\
\hline Berjejal & 11 & 78,5 \\
Tidak berjejal & 3 & 21,5 \\
Total & 14 & 100 \\
\hline
\end{tabular}

Tabel 5 memperlihatkan subjek penelitian dengan cara bernapas melalui mulut dan kondisi gigi anterior berjejal berdasarkan jenis kelamin. Pada penelitian ini subjek laki-laki lebih banyak dibandingkan perempuan.

Tabel 5. Distribusi bernapas melalui mulut dan gigi anterior berjejal berdasarkan jenis kelamin

\begin{tabular}{lcc}
\hline Jenis kelamin & n & \% \\
\hline Perempuan & 4 & 36,3 \\
Laki-laki & 7 & 63,4 \\
Total & 11 & 100 \\
\hline
\end{tabular}

Tabel 6 memperlihatkan subjek penelitian yang bernapas melalui mulut serta memiliki gigi anterior berjejal yang dibedakan berdasarkan usia. Subjek penelitian yang bernapas melalui mulut dan memiliki gigi anterior berjejal paling banyak terdapat pada usia 8 tahun $(54,5 \%)$.

Tabel 6. Distribusi subjek yang bernapas melalui mulut dan gigi anterior berjejal berdasarkan usia

\begin{tabular}{ccc}
\hline Usia & $\mathbf{n}$ & $\mathbf{\%}$ \\
\hline 8 & 6 & 54,5 \\
9 & 1 & 9,1 \\
10 & 3 & 27,3 \\
11 & 1 & 9,1 \\
Total & 11 & 100 \\
\hline
\end{tabular}

\section{BAHASAN}

Berdasarkan hasil penelitian yang dilakukan di SD Negeri 46 Manado melalui pemeriksaan objektif pada 64 siswa usia 612 tahun siswa laki-laki lebih banyak dari 
pada siswa perempuan. Siswa laki-laki lebih banyak daripada perempuan berhubung banyak siswa perempuan yang tidak menjadi subjek penelitian karena tidak diberikan izin dan tidak hadir saat penelitian dilaksanakan.

Siswa yang memiliki kebiasaan bernapas melalui mulut lebih sedikit dibandingkan siswa yang memiliki kebiasaan bernapas melalui hidung. Hal ini terjadi karena kebiasaan bernapas melalui mulut merupakan kebiasaan yang jarang dijumpai. Penelitian yang dilakukan oleh Gupitasari et $\mathrm{al}^{7}$ di Jember menunjukkan prevalensi kebiasaan buruk bernapas melalui mulut lebih kecil dibandingkan kebiasaan buruk lainnya.

Hasil penelitian ini memperlihatkan bahwa berdasarkan jenis kelamin lebih banyak siswa laki-laki memiliki kebiasaan bernapas melalui mulut dibandingkan pada siswa perempuan. Perbedaan jenis kelamin memengaruhi cara bernapas siswa. Kebiasaan bernapas melalui mulut lebih sering dialami oleh laki-laki karena pengaruh tingginya stres psikis. ${ }^{8} 9$ Penelitian yang dilakukan oleh Abbasi et $\mathrm{al}^{8}$ di Riyadh yang menyatakan kebiasaan bernapas melalui mulut pada siswa laki-laki lebih tinggi dibandingkan dengan siswa perempuan dikarenakan lebih aktifnya kegiatan yang dilakukan siswa laki-laki daripada siswa perempuan.

Siswa laki-laki cenderung lebih suka beraktivitas di luar ruangan dan bermain bersama teman-teman sesama jenisnya, seperti kejar-kejaran dan lebih memilih permainan sepak bola ataupun permainan lain yang menguras tenaga ketika jam pelajaran olah raga ataupun ketika ada waktu luang. Siswa laki-laki juga cenderung aktif di kelas dimana siswa laki-laki agak sulit untuk duduk diam berlama-lama di kelas, lebih suka mengitari ruang kelasnya, dan lebih cepat penasaran akan hal yang baru. Hal ini sering menyebabkan tingkat kelelahan yang tinggi pada siswa laki-laki sehingga memengaruhi kebiasaan bernapasnya yaitu menjadi bernapas melalui mulut agar dapat menghirup oksigen lebih banyak.
Selain aktivitas yang lebih tinggi, siswa laki-laki juga mengalami stres psikis yang lebih tinggi dibandingkan siswa perempuan. ${ }^{8}$ Dalam keluarga, anak laki-laki mempunyai beban harapan dari orang tuanya yang lebih tinggi, terutama dari sisi akademis dan prestasi lain yang dituntut harus lebih unggul, hal ini dapat menyebabkan stres psikis yang lebih tinggi pada siswa laki-laki.

Hasil penelitian ini menunjukkan siswa yang memiliki kebiasaan bernapas melalui mulut paling tinggi terjadi pada usia 8 tahun. Penelitian yang dilakukan oleh Zikari et al ${ }^{10}$ di Roma menyatakan tidak terdapat perbedaan bermakna antara kebiasaan bernapas melalui mulut dengan usia anak. Kebiasaan bernapas melalui mulut dapat dialami di berbagai usia. Pada penelitian ini kebiasaan bernapas melalui mulut paling banyak pada usia 8 tahun karena subjek penelitian paling banyak pada usia 8 tahun.

Dalam penelitian ini, selain karena pengaruh aktifnya kegiatan dan stres psikis yang dialami, kebiasaan bernapas melalui mulut dapat juga terjadi antara lain karena subjek menderita gangguan pernapasan yaitu penyakit asma. Subjek yang menderita penyakit asma pada penelitian ini sebanyak 3 orang, yaitu: 1) laki-laki berusia 8 tahun; 2) perempuan berusia 8 tahun; dan 3) lakilaki berusia 10 tahun. Penyakit asma menyebabkan penyempitan pada saluran pernapasan hingga aliran udara pernafasan tengganggu sehingga dapat memengaruhi cara bernapas anak. Penderita penyakit asma biasanya mengalami alergi rinitis dan eksema. Pada penderita asma yang disertai alergi rhinitis, biasanya hidung cenderung gatal yang membuat penderita sering menggosok hidung dengan tangan dan membuat penderita bernapas melalui mulut.

Pada penelitian ini terdapat 14 orang siswa yang bernpas melalui mulut dan $78,5 \%$ dari siswa tersebut memiliki gigi anterior berjejal. Siswa dengan cara bernapas melalui mulut dan memiliki gigi berjejal anterior paling banyak terdapat pada usia 8 tahun dan jenis kelamin laki-laki. Hal ini terjadi karena percepatan pertumbuhan (growth spurt) pada anak laki-laki yang 
berlangsung relatif lebih lambat dibandingkan anak perempuan.

Siswa yang bernapas melalui mulut banyak yang memiliki gigi berjejal; hal ini sesuai dengan penelitian yang dilakukan oleh Feroza et $\mathrm{al}^{9}$ di Banjarbaru yang melaporkan terdapatnya hubungan antara bernapas melalui mulut dan gigi berjejal. Pada anak yang memiliki kebiasaan bernapas melalui mulut terjadi aktivitas yang tidak normal pada musculus orbicularis oris, musculus genioglossus, musculus milohyoid, dan musculus masseter yang mengakibatkan pertumbuhan abnormal pada struktur wajah sehingga gigi menjadi berjejal.

Hasil penelitian ini mendapatkan bahwa gigi berjejal anterior lebih banyak pada pada siswa laki-laki dibandingkan siswa perempuan. Selain karena cara bernapas anak tersebut, hal ini juga dapat dipengaruhi oleh percepatan pertumbuhan (growth spurt) pada anak laki-laki yang berlangsung relatif lebih lambat selama beberapa tahun atau percepatan pertumbuhan yang lebih lambat pada anak laki-laki dibandingkan dengan anak perempuan yang dapat menyebabkan adanya proses adaptif pada gigi, tulang alveolar, rahang, dan jaringan lunak pada anak laki-laki. ${ }^{10}$

Kebiasaan bernapas melalui mulut jika dibiarkan terus-menerus maka dapat merubah bentuk dari kepala, rahang, dan lidah. Rahang bawah dan lidah letaknya lebih rendah dari posisi normalnya dan kepala akan memanjang. Bila perubahan postur ini dibiarkan, maka tinggi muka akan bertambah dan gigi posterior akan menjadi ekstrusi. Bila terjadi pertumbuhan ke arah vertikal dari tulang ramus, maka rahang bawah akan berotasi ke bawah dan ke belakang, sehingga menyebabkan open bite anterior dan overjet bertambah besar; hal ini akan meningkatkan tekanan pada pipi yang menyebabkan lengkung rahang atas menjadi sempit sehingga terjadilah gigi berjejal anterior. ${ }^{11} \mathrm{Hal}$ ini sesuai dengan penelitian yang dilakukan oleh Jefferson ${ }^{12}$ di New Jersey yang menyatakan bahwa terdapat hubungan antara bernapas melalui mulut dan gigi berjejal.
Gigi berjejal anterior pada anak dapat mengakibatkan beberapa gangguan pada penderitanya. Dilihat dari aspek fungsional, kemampuan untuk menggigit dan mengiris makanan terganggu karena posisi gigi yang tidak beraturan. Risiko terkena karies dan penyakit periodontal pada anak dengan gigi berjejal semakin tinggi karna sulitnya untuk membersihkan gigi berjejal tersebut. Gigi berjejal juga dapat memengaruhi psikologis yaitu menjadi kurang percaya diri karena penampilan anak tersebut.

\section{SIMPULAN}

Mayoritas anak di SD Negeri 46 Manado yang bernapas melalui mulut memiliki gigi berjejal anterior.

Disarankan untuk melakukan penelitian serupa dengan pengambilan sampel yang seimbang antara sampel yang bernapas melalui mulut dan yang bernapas melalui hidung agar gambaran yang didapatkan lebih akurat. Perlu dilakukan penelitian mengenai kebiasaan buruk lainnya yang dapat mengganggu oklusi.

\section{Konflik Kepentingan}

Penulis menyatakan tidak terdapat konflik kepentingan dalam studi ini.

\section{DAFTAR PUSTAKA}

1. Yuanisa S, Malik I, Saptarini R. Persentase maloklusi angle kelas II divisi 1 pada anak dengan kebiasaan bernafas melalui mulut. Jurnal Kedokteran Gigi Universitas Padjajaran. 2016;28(3): 191-6.

2. Kementerian Kesehatan Badan Penelitian dan Pengembangan Kesehatan. Hasil utama riskesdas 2018. Jakarta: Kementerian Kesehatan RI, 2018; p. 94.

3. Choudhary A, Gautman AK, Chousky A, Bhusan M. Interproximal enamel reduction in orthodontic treatment. JOADMS. 2015;1(3):123-7

4. Ma'al MI. Perbedaan indeks DMF-T dan OHI$S$ pada anak dengan susunan gigi berjejal, normal dan diastema di Sekolah Menengah Pertama Negeri 3 Dempet Demak. [Internet]. Indonesia. 2017. [cited 2019 July 1]. Available from: http://repository.unimus.ac.id/ 1339/3/BAB\%20II.pdf. 
5. Kementerian Kesehatan RI Pusat Data dan Informasi. Situasi Kesehatan Gigi dan Mulut. Jakarta: Kementerian Kesehatan RI, 2014; p. 2.

6. Riyanti E. Prevalensi maloklusi dan gigi berjejal berdasarkan jenis kelamin dan umur pada anak-anak sekolah dasar di Bandung. Jurnal Pengabdian Kepada Masyarakat. 2018;2(12):1-5.

7. Gupitasari A, Herniyati, Putri LSDA. Prevalensi Kebiasaan Buruk Sebagai Etiologi Maloklusi Klas I Angle Pada Pasien Klinik Ortodonsia RSGM Universitas Jember Tahun 2015-2016. e-Jurnal Pustaka Kesehatan. 2018;6 (2):365-70.

8. Abbasi AA. Alkadhi OH, Alhobail SQ, AlYami AS, Sarhani TM, Al Mejlad N, Prevalence of parafuctional oral habits in 7 to 15 years old school children in
Saudi Arabia. Journal of Orthodonthic \& Endodontics. 2017;3(4):1-4.

9. Feroza NA, Kusuma F, Wibowo D. Hubungan antara kebiasaan buruk bernapas melalui mulut dan tingkat keparahan maloklusi di SMPN 4 Banjarbaru dan SMAN 4 Banjarbaru. Dentino. 2017; 2(1):40-3.

10. Zicari AM, Albani F, Nterekou P, Rugiano A, Duse M, Mattei A. Oral breathing and dental maloclussion. Eur J Paediatr Dent. 2009;10(2):59-64.

11. Zenab Y. Menanggulangi kebiasaan buruk bernapas melalui mulut dengan oral screen [Makalah]. Bandung: Universitas Padjajaran; 2010.

12. Jefferson Y. Mouth breathing; adverse effect on facial growth, health, academics, and behavior. General Dentistry. 2010; 58(1):18-25. 